\title{
INTERCOMPARISON OF 51 RADIOMETERS FOR DETERMINING GLOBAL HORIZONTAL IRRADIANCE AND DIRECT NORMAL IRRADIANCE MEASUREMENTS
}

\author{
Aron Habte ${ }^{\mathrm{a}, 1}$, Manajit Sengupta ${ }^{\mathrm{a}}$, Afshin Andreas ${ }^{\mathrm{a}}$, Stephen Wilcox ${ }^{\mathrm{b}}$, Thomas Stoffel ${ }^{\mathrm{b}}$ \\ ${ }^{a}$ National Renewable Energy Laboratory, 15013 Denver West Parkway, Golden, CO 80401, USA \\ ${ }^{\mathrm{b}}$ Solar Resource Solutions, LLC, 249 Harper Street, Louisville, CO 80027, USA
}

\begin{abstract}
Accurate solar radiation measurements require properly installed and maintained radiometers with calibrations traceable to the World Radiometric Reference (WRR). This study analyzes the performance of 51 commercially available and prototype radiometers used for measuring global horizontal irradiances (GHI) or direct normal irradiances (DNI). These include pyranometers, pyrheliometers, rotating shadowband radiometers (RSR) ${ }^{2}$, and a pyranometer with an internal shading mask deployed at the National Renewable Energy Laboratory's (NREL) Solar 13 Radiation Research Laboratory (SRRL). The radiometers in this study were deployed for one year (from April 1, 14 2011, through March 31, 2012) and their measurements were compared under clear sky, partly cloudy, and mostly 15 cloudy conditions to reference values of low estimated measurement uncertainties. Mean Bias Difference (MBD) 16 and Root Mean Square Difference (RMSD) statistics were used as metrics to compare the GHI and DNI values 17 from individual instruments with concurrent measurements using the reference instruments over time intervals of 18 one-minute, 10-minute, and hourly averages. Deviations from the reference irradiance measurements were 19 calculated as a percent and $\mathrm{W} / \mathrm{m}^{2}$ of the reference value for solar zenith angles ranging from 17.5 degrees to 85 20 degrees (the range of available solar zenith angles throughout the year at SRRL, excluding data near sunrise and 21 sunset). Under clear-sky conditions when the solar zenith angle was less than 60 degrees, differences of less than $22 \pm 5 \%$ were observed among all GHI and DNI measurements when compared to the reference radiometers. For GHI 23 these normalized differences increased up to $\pm 17 \%$ under mostly-cloudy and clear-sky conditions when the solar 24 zenith angle was greater than 60 degrees. The normalized differences were greater yet under mostly- cloudy 25 conditions (approaching $\pm \mathbf{4 0 \%}$ ) for few DNI data sets at higher solar zenith angles. The intent of this paper is to 26 present a general overview of each radiometer's performance based on the instrumentation and environmental 27 conditions available at NREL.
\end{abstract}

29 Keywords: Global Horizontal Irradiance; GHI; Direct Normal Irradiance; DNI; Diffuse Horizontal Irradiance; DHI; 30 Pyranometer; Pyrheliometer; Rotating Shadowband Radiometer; RSR;

\footnotetext{
${ }^{1}$ Corresponding author. Tel: +1 303384 6389; fax: +1 3033846391

E-mail: aron.habte@nrel.gov

${ }^{2}$ In 2011, IEA Task 46 activity B1 adopted the name Rotating Shadowband Irradiometers (RSI) to categorize this type of measurement systems
} 


\section{INTRODUCTION}

Accurate solar radiation measurement is essential for reducing the risks associated with the increased deployment of solar energy conversion systems on a variety of generation scales throughout the world (Habte et al.,

4 2015). For instance, in order to finance these systems through a power purchase agreement (PPA), banks demand

5 assurances that these systems will produce the energy predicted through performance models. Failing to meet the minimum energy performance requirements can result in large financial penalties requiring expensive risk mitigation measures. Since 1981, the Solar Radiation Research Laboratory (SRRL) at the National Renewable Energy Laboratory in Golden, Colorado, USA has provided a continuous record of solar irradiance and surface meteorological conditions, improved methods for the calibration of radiometers and dissemination of solar resource data through the Measurement and Instrumentation Data Center (MIDC) (Andreas and Stoffel, 1981). MIDC provides historical solar data from multiple radiometers with calibration traceability to the Système International d'Unités through the World Radiometric Reference (WRR) (Fröhlich 1977 and Fröhlich 1991, Stoffel and Reda,

\section{MATERIALS AND METHODS} from various radiometers under a wide range of sky conditions with respect to a measurement reference demonstrating low estimated measurement uncertainty. Some of the variables contributing to the observed differences include radiometer calibrations and each instrument's unique response characteristics to variations in solar zenith angle, solar and atmospheric spectral irradiance distributions, temperature, installation (e.g., sensor tilt), aging, nonlinearity, and other environmental conditions. The solar measurements from the radiometers were quality assessed to minimize erroneous data used in our analyses. However, our results are presented with some caveats: (1) A sufficient number of radiometers for each model were not available to provide representative sample data for each manufacturer's product. (2) In our professional experience, we have found that each instrument responds differently under various climatic/weather conditions; thus, these results are specific to the conditions encountered at SRRL in Golden, Colorado, USA (39.742 ${ }^{\circ} \mathrm{N}, 105.18^{\circ} \mathrm{W}, 1,829 \mathrm{~m}$ AMSL) during the period of analysis (April 1, 2011 through March 31, 2012). (3) Solar irradiance at the Earth's surface is extremely variable over space and time, and the reference and test instruments have different inherent responses to changes in solar and atmospheric radiation, spectral radiation distribution, incidence angle of the incoming radiation (e.g., pyranometer cosine response), thermal offset and temperature sensitivities. Thus, while some instrument performance characteristics may be similar in other operational environments, the limited data set and specific location used for this study should not be used to infer comprehensive conclusions of radiometer performance beyond the context of the evaluations. This paper intends to provide the reader with a general understanding about how each radiometer behaves under specific documented conditions when compared to the selected reference data.

Most of the instruments in this study are owned by NREL as part of our ongoing Baseline Measurement System (BMS). For this study, additional instruments were provided by the manufacturers at the request of NREL or as part of a Cooperative Research and Development Agreement (CRADA). A complete list of instruments is provided as Table 1 and Table 2 . The manufacturers were allowed to select the instruments they provided, and NREL made no effort to ensure that they were representative of typical production units. In the case of 
manufacturer-owned instruments, prior to the start of the evaluation period, the manufacturers were allowed to ensure that their instruments were installed and operating to their satisfaction. After the evaluation period began, the manufactures were not allowed any contact or interaction with the instruments. All data collected from the instruments for this study were downloaded directly to NREL computers. The Solar Millennium instrument (SolarMil.-CRADA-RSR) was set up by the manufacturer with special internal processing to take the place of the external processing that is usually provided by the manufacturer on corporate servers. As noted below, this necessitated the omission of the instrument's usual one-minute data output.

The performance of each test instrument relative to the reference instrument was analyzed using the Mean

Bias Difference (MBD) and Root Mean Square Difference (RMSD) statistics. One-minute reference global horizontal irradiance (GHI) data were calculated using the reference direct normal irradiance (DNI) and diffuse horizontal irradiance (DHI) instruments. The reference GHI and DNI data and unit under test (UUT) GHI and DNI data were then averaged to obtain 10-minute and hourly data. The 10-minute data were averaged from the observed one-minute data- except for the Solar-Mil.-CRADA-RSR, which recorded the data as 10-minute averages. The hourly data for all radiometers were averaged from the 10-minute data sets.

Data from 32 GHI and 19 DNI radiometers are presented in Table 1and Table 2. Reference values of GHI were calculated using a reference DNI and a reference DHI using the component sum method (Equation 1). The performance of each instrument was derived from time-series measurements relative to the corresponding reference irradiance. Reference DNI data were obtained using a Kipp and Zonen model CH1 pyrheliometer (serial number 010256), and reference DHI measurements were made by two Eppley Laboratory, Inc., model 8-48 pyranometers (serial number 21096 was replaced for re-calibration on May 26, 2011 by 32331). The 8-48 ("black and white") pyranometers were not ventilated. The DHI data for the two Eppley model 8-48 pyranometers were analyzed for any systematic shift in the reference DHI data. . A comparison of one-minute measurements of GHI/DHI under clear sky conditions for five days prior to and five days after the instrument exchange suggested no significant shift between the two DHI reference pyranometers. Furthermore, $85 \%$ of the reference DHI data included in this paper came from the Eppley model 8-48, serial number 32331 (May 26, 2011 to March 31, 2012). The reference DNI and DHI instruments were mounted in an automatic solar tracker to provide accurate and continuous alignment of the pyrheliometer and the shading device for the pyranometer. Previous studies (Wilcox and Myers 2008, Michalsky et al. 2011) and Broadband Outdoor Radiometer Calibration (BORCAL) ${ }^{3}$ results from these instruments confirm that the $\mathrm{CH} 1$ exhibits relatively lower calibration and measurement uncertainty compared to others in the sample. For consistency with our previous study, the model 8-48 pyranometer for the diffuse measurement was selected instead of an available model CM22 pyranometer to minimize a possible systematic design bias that might favor the reference GHI values.

\footnotetext{
${ }^{3}$ BORCAL reports are available from http://www.nrel.gov/aim/borcal.html
} 


\subsection{Data Logging}

The irradiance measurements were recorded as one-minute averages of three-second samples for most radiometers. The ATI radiometer was recording two-second samples, the TSR radiometers were recording every 15 seconds and the Hukseflux radiometers recorded one second samples. For these radiometers the data were recorded using Campbell Scientific, Inc., data loggers. The exceptions are the Solar-Mil.-CRADA-RSR where the data were

\subsection{Reference Data}

\subsubsection{Correcting Reference Data for Temperature Dependence}

The manufacturer specifications state the temperature dependencies of the reference radiometers (Figure 1). The temperature dependency function from Figure 1 was used to correct the reference irradiance data obtained from the reference radiometers based on the coincident meteorological measurements of air temperature.
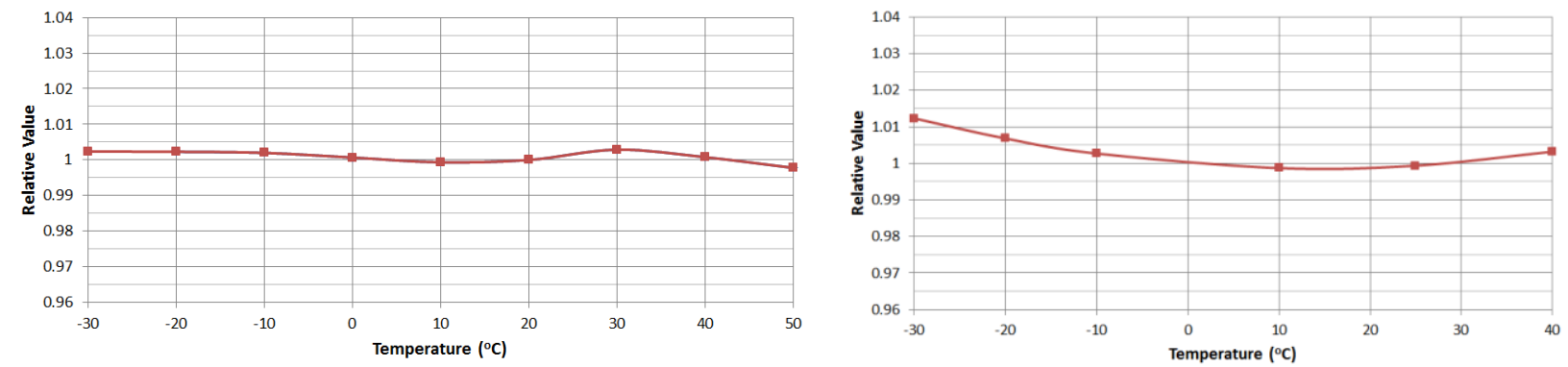

Figure 1. Temperature dependencies for the Kipp and Zonen model CH1 (left) and (right) the Eppley Laboratory, Inc., model 8-48 reference radiometers.

This correction process resulted in an approximate $\pm 0.08 \%$ difference on average for both DNI and 


\subsection{Measurement Uncertainty}

Each instrument, including the reference instruments, had its own estimated measurement uncertainty based on the design and performance specifications. The measurement uncertainty analysis and estimation is beyond 4 the scope of this paper ${ }^{4}$. Previous work by Reda et al., 2011 and Habte et al., 2014 describe the methodology of radiometric measurement uncertainty estimation using the Guide to the Expression of Uncertainty in Measurement (GUM; JCGM, 2008). The calibration and measurement uncertainty estimates of the reference and test radiometers are essential to properly interpret the reported differences obtained in this study. That is, observed differences among the radiometers must be greater than the uncertainty estimates to be considered measurable. Habte et al., 2015 reported about $\pm 2.1 \%$ uncertainty for the GHI reference data and about $\pm 1 \%$ for the reference DNI data. The percent uncertainties are obtained from the average irradiance reading of the study period and include the calibration uncertainties of the reference radiometers. Further the CR23X Campbell Scientific data logger used to acquire the study data contributes to the overall uncertainty. Wilcox and Myers, 2008 reported around $\pm 1.5 \%$ uncertainty from the data logger to the average reference irradiance. Therefore, the expanded or overall uncertainties (coverage factor

$14=1.96$ ) of the reference data would be the root sum of the squares of the irradiance and the data logger uncertainty, 15 resulting in $\pm 2.6 \%$ and $\pm 1.8 \%$ for reference GHI and DNI, respectively. Hence, in this paper the reported differences 16 between the reference data and the unit under test (UUT) would be statistically significant if the difference is greater 17 than the overall reference data uncertainty.

\section{$18 \quad 2.4$ Data Quality}

19 Multiple post-measurement data quality schemes were applied to the radiometric data. Some of these 20 schemes target detecting equipment and operational related errors and data issues as a result of contaminated optics.

\subsubsection{SERI_QC}

A data quality assessment software tool (SERI_QC) was applied to each data point (Maxwell, et al., 1993).

\subsection{Operation and Maintenance}

Proper installation, operation and maintenance of the instruments are critical for measuring accurate solar resources. The installation of all instruments at SRRL is consistent with current best practices (Sengupta et al., 33 2015). Cleaning radiometer optical surfaces on a regular basis minimizes the attenuation of the signals by

\footnotetext{
${ }^{4} \mathrm{~A}$ tool for estimating radiometer measurement uncertainties is available from http://www.nrel.gov/midc/radiometer_uncert.xlsx
} 
contaminates. However, in some cases, accumulation of snow or frost could create greater statistical differences between the reference and unit under test (UUT) because some instruments tend to accumulate more snow or frost than others. To minimize the effect of this accumulation, some of the pyranometers are equipped with ventilators as noted in Table 1. Proper leveling of the pyranometers is essential to avoiding any asymmetric responses by these radiometers throughout the day. Checking desiccants, when part of the radiometer design, is important for preventing condensation inside the optical surfaces, which would affect the signal. Further, regularly checking the signal cable condition can help to prevent data loss or signal contamination. However, these problems might not have been completely detected and removed by the SERI_QC software.

Some instruments have built-in post-measurement correction algorithms that are applied by the onboard data logger for known instrument response characteristics. These corrections are applied by the manufacturer during routine data acquisition and were available in the instrument output data set used for this study. Further, the Eppley model Precision Spectral Pyranometer (PSP) used in this study has correction algorithms developed and applied by NREL (Andreas and Stoffel, 1981; Reda, 1998). A thermal correction to GHI data using coincident measurements of infrared irradiance by a collocated pyrgeometer and a correction to the GHI pyranometer responsivity as a function of the solar zenith angle were implemented in the study. Results for both the uncorrected PSP (as typically deployed) and the NREL-corrected PSP are included in our study. The three Yankee model TSR instruments had experimental post-processing applied to test research algorithms under development (Michalsky et. al., 1987). The same instruments were used for measurements, and the sensor data were replicated into three different data streams, each treated as independent instruments by the study (e.g., TSR-59x, TSR-59x-LH and TSR-59x-JM).

\subsection{Data Filtering}

Selected data points were excluded from the analysis to maintain a consistent comparison among instruments for the 12-month period. If data were excluded from one instrument, data from the same period were excluded from all instruments. The exception was the Yankee model Thermopile Shadowband Radiometer 591 (TSR-591), which had incorrect or no data for the month of November 2011. To minimize the loss of data in the analysis from all the UUT, we did not include data fromTSR-591, TSR-591-LH and TSR-591-JM in the filtering process for the November 2011.

The study included only daytime data (e.g., solar zenith angles less than or equal to 85 degrees). Some data 28 points at solar zenith angles approaching 85 degrees (i.e., periods with typically low solar irradiance levels) were 29 excluded from the analysis to avoid the effects of large relative differences during the low absolute magnitude of irradiance near sunrise and sunset. Therefore, differences greater than $\pm 100 \%$ were excluded from the final analysis for all UUT radiometers. This criterion is consistent with a previous study (Wilcox and Myers 2008).

Furthermore, concurrent data from a Yankee Environmental Systems, Inc., total sky imager (TSI) model 33 TSI-880 were used to categorize irradiance data from all the instruments according to clear, partly-cloudy, and 34 mostly-cloudy sky conditions. The total cloud cover percentage from the TSI-880 instrument was used for this classification. The instrument provides high-resolution, one-minute data that coincide with the radiometric data. In our experience, the instrument tends to underestimate cloud cover, and for this reason a simple criterion that 37 mitigates the problem was developed to distinguish cloud cover ranges. Sky condition categories were determined as 
1 follows: Clear sky conditions when TSI total cloud cover data were less than $1.2 \%$; partly- cloudy from $1.2 \%$ to $60 \%$; and mostly-cloudy when TSI total cloud cover data were greater than $60 \%$.

\subsection{Data Normalization}

To remove potential instrument calibration biases and to better isolate the environmental effects, the annual radiometric data from the test instruments were normalized to the reference irradiance data. Normalization was done by isolating the irradiance data under all sky conditions for the study period (April 1, 2011, through March 31, 2012) between 44- and 46-degree solar zenith angles and summing all the data in this solar zenith angle range for each radiometer. The specified solar zenith angle range was selected to conform to the NREL convention of reporting all broadband radiometer calibrations at a 45-degree solar zenith angle (Myers et al., 2000). A ratio was then obtained by dividing each test radiometer summation by the sum of the reference data derived using the same criterion. The ratio for each test radiometer was then used to acquire the new normalized irradiance value by dividing each test irradiance value for the time interval by the normalization ratio (Equation 2):

$$
\text { Normalization Factor }=\frac{\sum I_{U U T_{44}}{ }^{\circ} \text { to } 46^{\circ}}{\sum I_{R e f_{44}}{ }^{\circ} \text { to } 46^{\circ}}
$$

where $I_{U U T 44}{ }_{\text {to }} 4^{\circ}$ is the irradiance data under all sky condition for the UUT within the two-degree solar zenith angle 15 bin and $I_{\text {Ref } 44}{ }_{\text {to }}{ }^{\circ} 6^{\circ}$ is the irradiance data of the reference instrument within the same solar zenith angle range.

The new normalized irradiance data from the UUT were then computed as (Equation 3):

$$
I_{U U T(\text { New })}=\frac{I_{U U T}}{\text { Normalization Factor }}
$$

The adjustments used to normalize the data for each instrument are included in Table 1 and Table 2 as the Normalization Factor column. Comparing calibration methods is beyond the scope of this paper, but the factors listed in the two tables will provide users with an indication of possible variances among calibration techniques that could affect the accuracy of their measurements. A normalization factor greater than one indicated that the UUT data were higher than the reference radiometer measurement. A normalization factor lower than one meant that the UUT was underestimating irradiance relative to reference data.

Overall, as shown by the values in Table 1and Table 2, the data normalization process presented an approximate range of $\pm 5 \%$ compared to the un-normalized data for both the GHI and DNI data sets. This statistic should not be interpreted or included as a quantified uncertainty for each instrument, as it is intentionally independent of the results presented here. It is included to educate the user of possible calibration bias in field measurements and to convey a full understanding of the study method. Note that most of the normalizations for NREL-calibrated instruments are within $\pm 1 \%$, indicating a consistency at the study location. However, instruments calibrated at NREL have demonstrated a shift in calibration when moved to another location and environment. The same may be true for instruments calibrated at other locations using other methods, which may be in part revealed 32 by the normalization statistic. This underscores our assertion that these results cannot be used to infer instrument 33 behavior at all locations. 
Table 1: GHI Instrument List

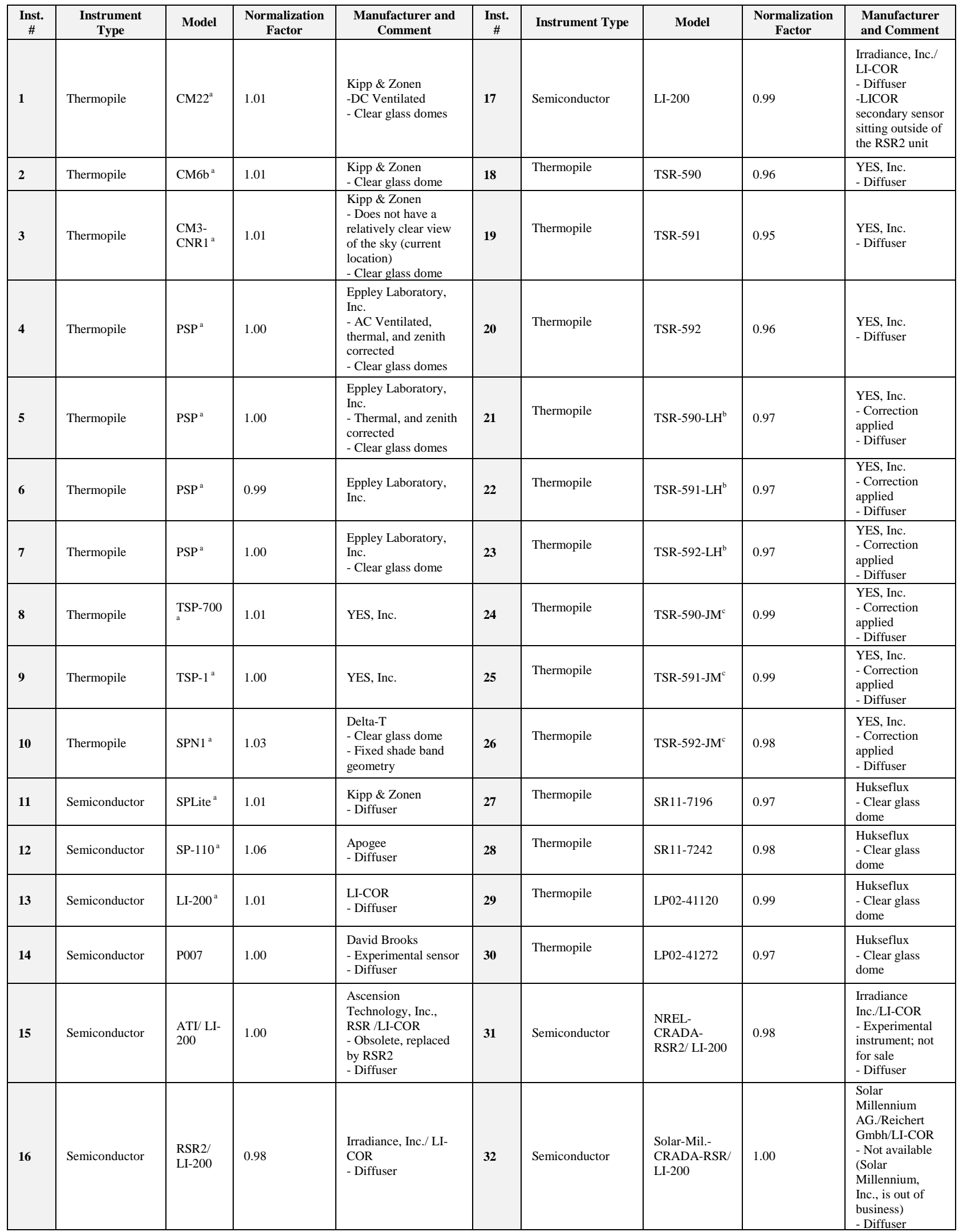


1 Current NREL calibration factor used during the period of the evaluation

$2 \quad{ }^{b}$ Empirical Radiometric Correction applied by Lee Harrison (Michalsky et. al., 1987)

$3 \quad{ }^{\mathrm{c}}$ Empirical Radiometric Correction applied by Joseph Michalsky (Michalsky et. al., 1987)

Table 2: DNI Instrument List

\begin{tabular}{|c|c|c|c|c|}
\hline Inst. \# & Instrument Type & Model & Normalization Factor & Manufacturer/Comment \\
\hline 1 & Thermopile & $\mathrm{NIP}^{\mathrm{a}}$ & 0.99 & $\begin{array}{c}\text { Eppley Laboratory, Inc. } \\
\text { - Glass window } \\
\text { (Normal Incidence Pyrheliometer, sample 2) }\end{array}$ \\
\hline 2 & Thermopile & NIP $^{a}$ & 0.99 & $\begin{array}{c}\text { Eppley Laboratory, Inc. } \\
\text { - Glass window } \\
\text { (Normal Incidence Pyrheliometer, sample 1) }\end{array}$ \\
\hline 3 & Semiconductor & LI-201 a & 0.94 & $\begin{array}{c}\text { LI-COR } \\
\text { - Experimental instrument; not for sale } \\
\text {-Diffuser }\end{array}$ \\
\hline 4 & Semiconductor & $\mathrm{ATI} / \mathrm{LI}^{-\mathrm{COR}^{\mathrm{b}}}$ & 1.04 & $\begin{array}{c}\text { Ascension Technology Inc./LI-COR } \\
\text { - Obsolete, replaced by RSR2 } \\
\text { - Diffuser }\end{array}$ \\
\hline 5 & Semiconductor & $\mathrm{RSR} 2 / \mathrm{LI}^{-\mathrm{COR}^{\mathrm{b}}}$ & 0.98 & $\begin{array}{c}\text { Irradiance Inc./LI-COR } \\
\text { - Diffuser }\end{array}$ \\
\hline 6 & Thermopile & TSR- $590^{\mathrm{b}}$ & 0.99 & $\begin{array}{l}\text { YES, Inc. } \\
\text {-Diffuser }\end{array}$ \\
\hline 7 & Thermopile & TSR-591 ${ }^{\mathrm{b}}$ & 0.97 & $\begin{array}{l}\text { YES, Inc. } \\
\text { - Diffuser }\end{array}$ \\
\hline 8 & Thermopile & TSR-592 ${ }^{\mathrm{b}}$ & 0.99 & $\begin{array}{l}\text { YES, Inc. } \\
\text { - Diffuser }\end{array}$ \\
\hline 9 & Thermopile & TSR-590LH ${ }^{\mathrm{b}}$ & 0.99 & $\begin{array}{l}\text { YES, Inc. } \\
\text { - Diffuser }\end{array}$ \\
\hline 10 & Thermopile & TSR-591LH $^{\mathrm{b}}$ & 0.98 & $\begin{array}{l}\text { YES, Inc. } \\
\text { - Diffuser }\end{array}$ \\
\hline 11 & Thermopile & TSR-592LH ${ }^{\mathrm{b}}$ & 0.99 & $\begin{array}{l}\text { YES, Inc. } \\
\text { - Diffuser }\end{array}$ \\
\hline 12 & Thermopile & TSR-590JM $^{\mathrm{b}}$ & 0.98 & $\begin{array}{l}\text { YES, Inc. } \\
\text { - Diffuser }\end{array}$ \\
\hline 13 & Thermopile & TSR-591JM $^{\mathrm{b}}$ & 0.97 & $\begin{array}{l}\text { YES, Inc. } \\
\text { - Diffuser }\end{array}$ \\
\hline 14 & Thermopile & TSR-592JM $^{\mathrm{b}}$ & 0.97 & $\begin{array}{l}\text { YES, Inc. } \\
\text { - Diffuser }\end{array}$ \\
\hline 15 & Semiconductor & NREL-CRADA-RSR2/LI-COR ${ }^{b}$ & 0.98 & $\begin{array}{c}\text { Irradiance Inc./LI-COR } \\
\text { - Experimental instrument. Not for sale. } \\
\text { - Diffuser }\end{array}$ \\
\hline 16 & Thermopile & SPN1 ${ }^{a b}$ & 1.05 & $\begin{array}{c}\text { Delta-T } \\
\text { - Clear glass dome }\end{array}$ \\
\hline 17 & Thermopile & DR018066 & 0.97 & $\begin{array}{c}\text { Hukseflux } \\
\text { - Glass window }\end{array}$ \\
\hline 18 & Thermopile & DR018068 & 0.98 & $\begin{array}{c}\text { Hukseflux } \\
\text { - Glass window }\end{array}$ \\
\hline 19 & Semiconductor & $\begin{array}{l}\text { Solar-Mil.-CRADA-RSR/ LI- } \\
\text { COR }^{\mathrm{b}}\end{array}$ & 1.00 & $\begin{array}{c}\text { Solar Millennium AG./Reichert Gmbh/LI-COR } \\
\text { - Not available (Solar Millennium, Inc., is out of business) }\end{array}$ \\
\hline
\end{tabular}

$4{ }^{\mathrm{a}}$ Current NREL calibration factor used during the period of the evaluation

$5 \quad{ }^{\mathrm{b}}$ Calculated using global and diffuse measurements 


\section{RESULTS AND DISCUSSION}

\subsection{Comparison Result for Global Horizontal Irradiance Radiometers}

The figures and tables discussed in the results section show the performance of each unit under test (UUT) instrument relative to the reference instrument under various sky conditions. Mean Bias Difference (MBD) and Root Mean Square Difference (RMSD) statistics were used as the basic set of performance measures to assess the performance of each UUT relative to the reference instruments. MBD calculations both in percent and power density in watts per square meter square $\left(\mathrm{W} / \mathrm{m}^{2}\right)$ were used to assess radiometer performance (Equation 4$)$. Further, supplemental meteorological measurements such as temperature and wind speed from the collocated instruments were used to assist in the analysis. Each radiometric data value from the test instruments demonstrated systematic differences as a function of solar zenith angle, temperature, and wind speed.

$M B D\left(W / m^{2}\right)=\frac{1}{n} \sum_{i=1}^{n}\left(I_{U U T(N e w)_{i}}-I_{\text {Ref }_{i}}\right) \quad$ and $\quad M B D(\%)=\left(\frac{1}{n} \sum_{i=1}^{n} \frac{\left(I_{U U T(N e w)}-I_{\text {Ref }_{i}}\right)}{I_{\text {Ref }_{i}}}\right) * 100$

where, $I_{U U T(N e w)}$ is the irradiance value for the UUT in $\mathrm{W} / \mathrm{m}^{2}$ and $I_{\text {Ref }}$ is the irradiance value for the reference instrument in $\mathrm{W} / \mathrm{m}^{2}$.

RMSD demonstrates the randomness in the data, and the calculation was performed in percent differences using Equation 5.

$$
\operatorname{RMSD}(\%)=\sqrt{\left(\frac{1}{n} \sum_{i=1}^{n}\left(\frac{I_{U U T\left(\text { New }_{i}-I_{\text {Ref }}\right.}}{I_{\text {Ref }_{i}}}\right)^{2}\right)} * 100
$$

Figure 2 and Figure 3 demonstrate the 10-minute and hourly average GHI data comparsion, respectively, for all instruments under test. The ranges of MBD and RMSD in percent are shown for each instrument. These plots demonstrate the relative tendencies or performance of each instrument with respect to the references used in our study. As shown in the figures, the plots are bounded by $\pm 20 \%$ MBD for GHI. Data points outside of these bounds were not included in the statistical analyses. These criteria helped limit the contribution of outlying high-percentage differences that could have resulted from time response differences among the instruments, performance disruptions during routine cleaning events, and/or erroneous observations for unknown reasons. Further, Figure 2 and Figure 3 illustrate the skewness of the differences when the MBD (\%) tended to the positive on some of the instruments and negative on others. These characterisitic differences assisted in identifying the overestimation or underestimation of irradiance by each UUT instrument. Under clear-sky condtions, the relative difference appeared to exhibit less bias and the mean differences (red line) for most UUT tended to have less variability than the partly-cloudy or mostlycloudy sky condition. One important aspect to note from Figure 2 and Figure 3 is that the sizes of the 95\% confidence interval indicated by the black boxes, provide valuable information about the scatter of the differences between the reference instrument and the UUT. Smaller/larger ranges of the 95\% confidence intervals depict smaller/larger differences in the comparative data. Further, UUT instruments that showed higher variability above 
1 the confidence interval box, either to the positive or negative trend, tended to have relatively lower performance

2 characteristics in the higher zenith angle ranges. (See Appendix - Table A.1. for individual instrument performance.)
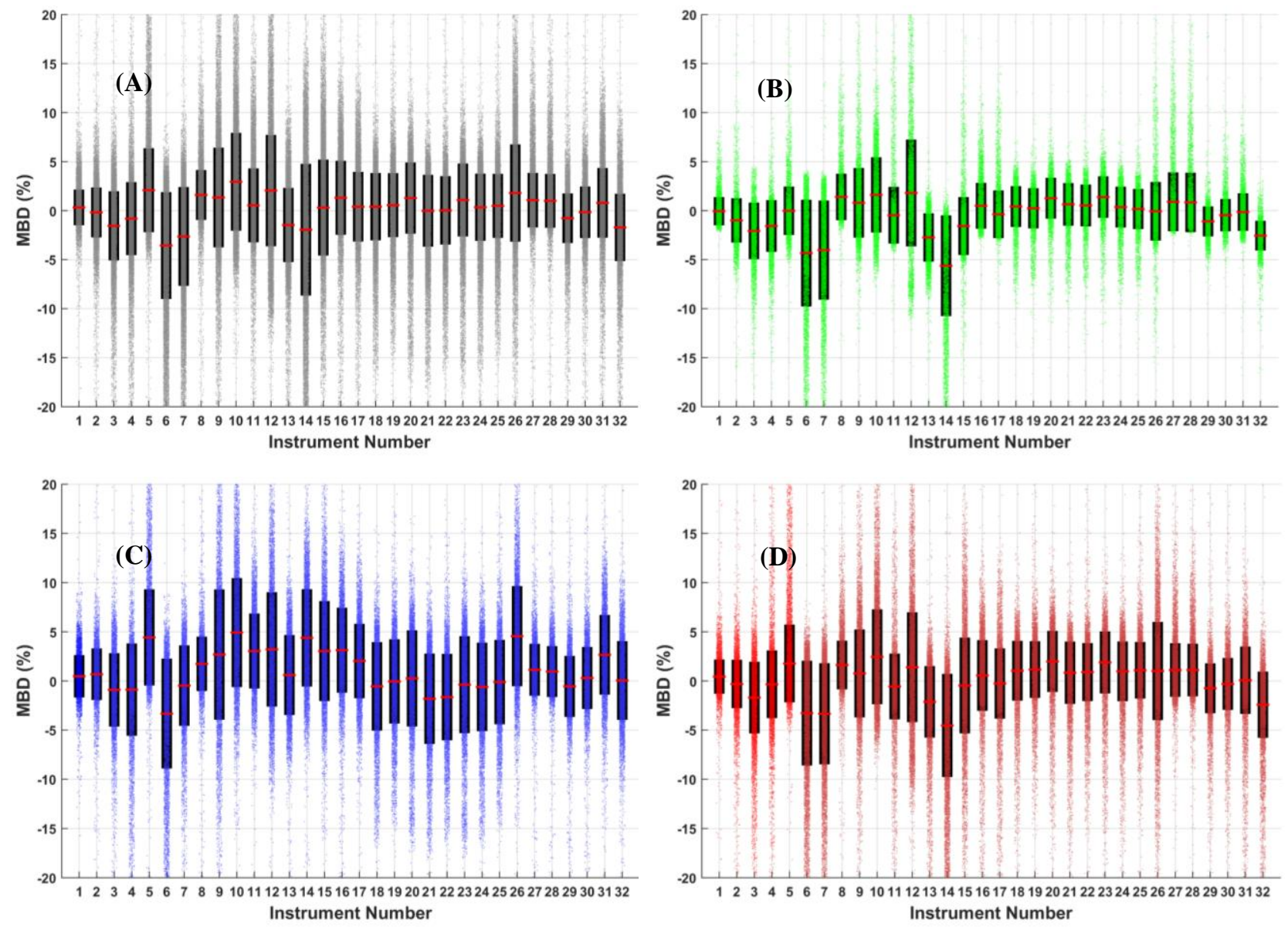

Figure 2. MBD in percent for the 10-minute average GHI data under study ((A) all sky, (B) clear sky, (C) mostlycloudy sky, and (D) partly-cloudy sky). The red line signifies the mean value of the MBD for the 95\% confidence level (black color - box). See Table 1 for the instrument number, name and model.

The 10-minute average data showed more scatter than found in the hourly-averaged results. (Compare the 

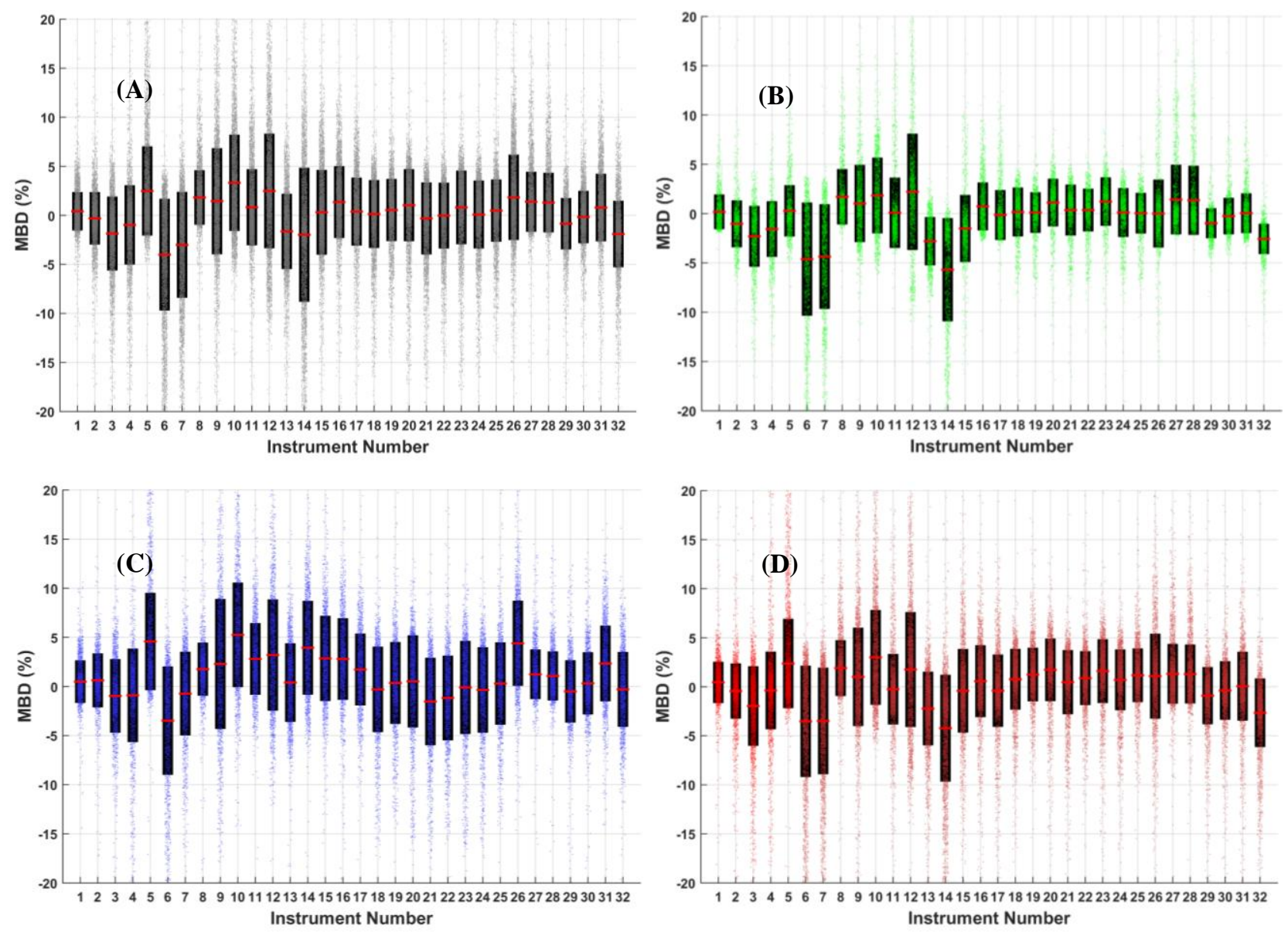

Figure 3. MBD in percent for the hourly averaged GHI data under study ((A) all sky, (B) clear sky, (C) mostly cloudy sky, and (D) partly cloudy sky). The red line signifies the mean value of the MBD for the 95\% confidence level (black color - box). See Table 1 for the instrument number, name and model.

The MBD values shown in Appendix - Table A.1. present all differences within a $\pm 100 \%$ data exclusion range. There could have been outliers that were close to the data exclusion range that might have affected the overall MBD average in each bin of the higher solar zenith angle and mostly-cloudy conditions. These two situations included irradiance values of a very small magnitude, and ratios of two small irradiance numbers will produce high MBD in percent (the yellow highlighted values in Appendix - Table A.1.).

Figure 4 presents the RMSD results for GHI in percent. As can be expected during stable atmospheric conditions, all instruments had relatively low RMSD values during clear-sky conditions than during partly- and mostly-cloudy sky conditions. These results can be largely attributed to the differing instrument response characteristics (e.g., time-response, spectral response, and etc.) invoked under changing sky conditions (Vignola, Stoffel, and Michalsky 2012). The fast responding photodiode instruments may exhibit greater RMSD than the slower response thermopile instruments. Some of this may be a false representation of where the measurement difference originates (i.e., with the reference instrument rather than the UUT). 
Further, both the MBD and RMSD values should be taken into consideration (e.g., Figure 2 through Figure

4) to understand the performance of each instrument relative to the reference instrument. For instance, one instrument could have less bias but higher RMSD; therefore, an instrument with less bias and less RMSD would perform similarly to the reference data. This also applies to the DNI data set comparison, which is discussed in Section 3.2.
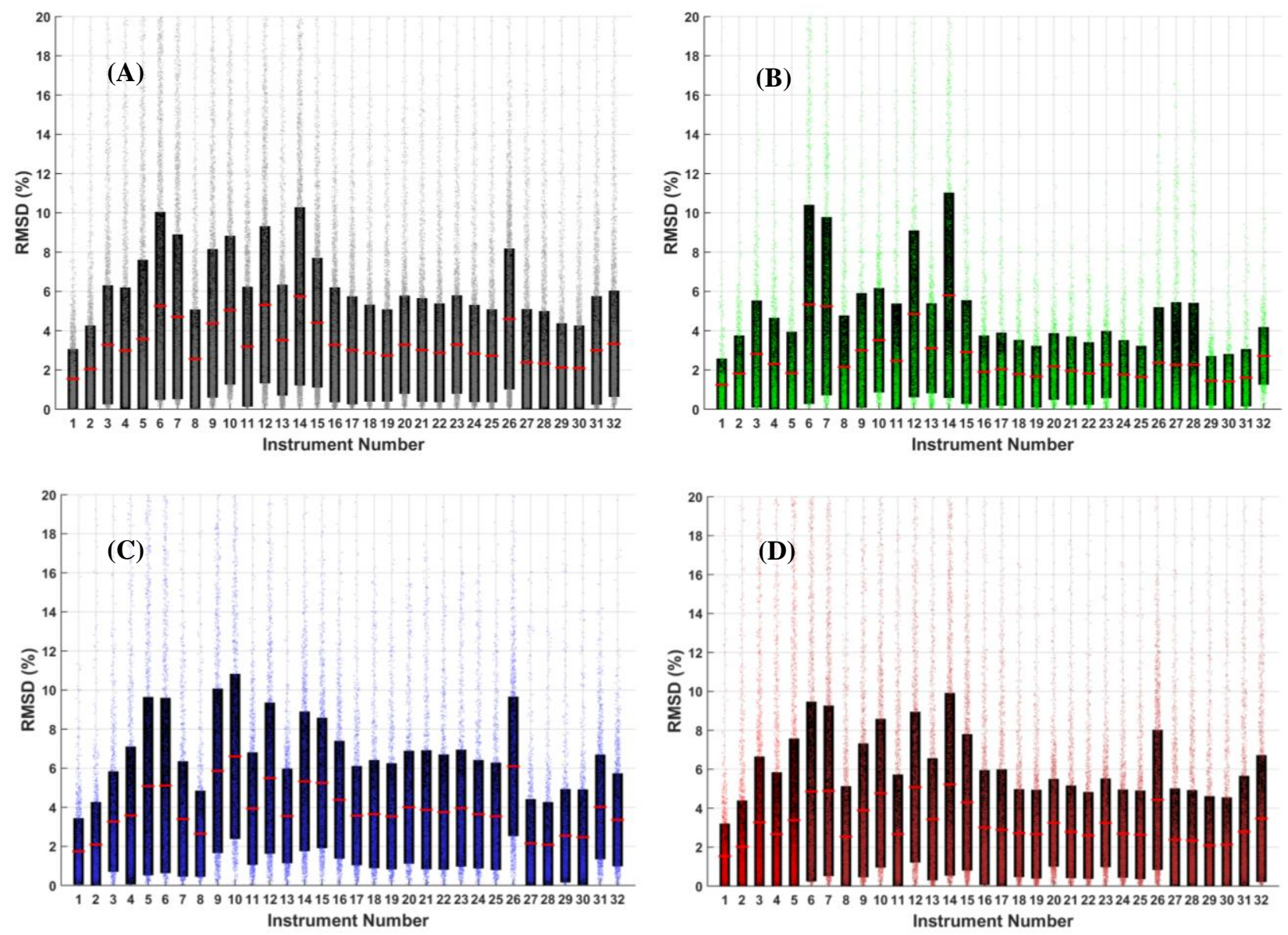

Figure 4. RMSD in percent for the hourly average GHI data under study ((A) all sky, (B) clear sky, (C) mostly cloudy sky, and (D) partly cloudy sky). The red line signifies the mean value of the RMSD for the 95\% confidence level. Refer to Table 1 for the instrument number, name and model.

\subsubsection{Photodiode Pyranometer Characteristics}


1 used in thermopile-based radiometers. Photodiode detectors are fast-responding sensors (e.g., less than $1 \mu$ sec for 1/e) and are calibrated to a thermopile spectral range ( $300 \mathrm{~nm}$ to $4,000 \mathrm{~nm}$ ).

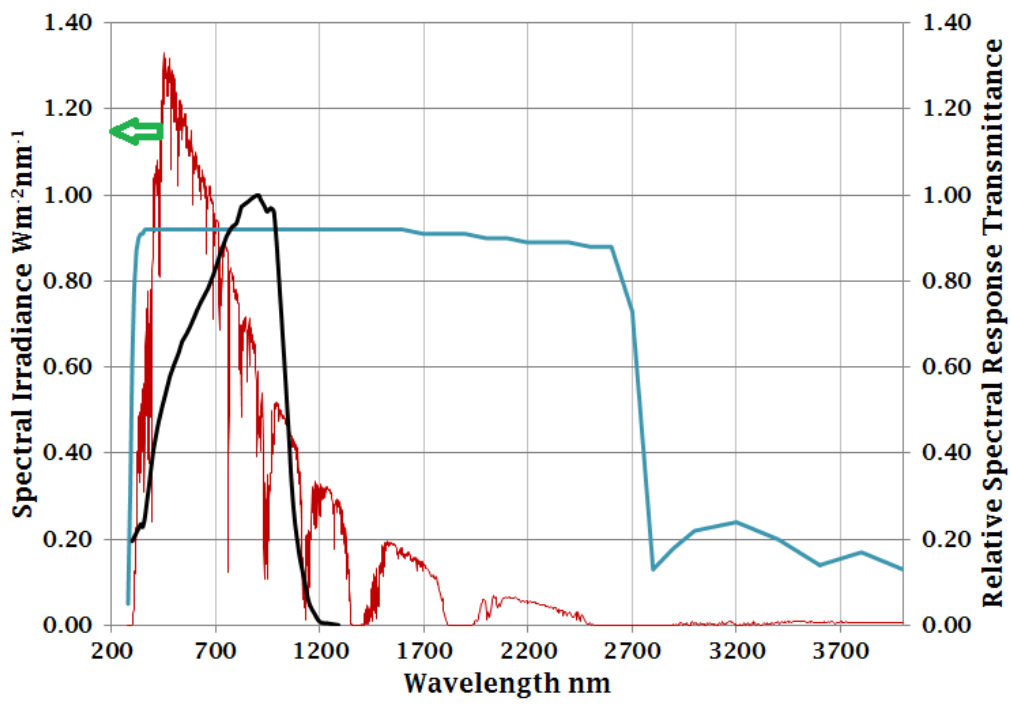

Figure 5. GHI solar spectrum with thermopile and silicon photodiode pyranometers spectral response (modified

Silicon photodiode pyranometers tend to have reasonable accuracy under the calibration conditions, but

7 have spectral, angular, and temperature sensitivity characteristics that contribute to significant differences under

8 measurement conditions differing from the calibration conditions. Post-measurement correction methods have been

9 developed for pyranometers based on photodiode detectors (Myers 2011, Vignola 2006, King and Myers 1997). The

10 NREL-CRADA-RSR2 instrument has a built-in correction algorithm in the data acquisition system supplied by the 11 manufacturer (Irradiance, Inc.). These algorithms apply different correction methods to minimize the above-

12 mentioned issues. It appears that the application of such algorithms in the NREL-CRADA-RSR2 minimized the 13 deviation of the data relative to the reference instrument (Refer to Appendix - Table A.1. for NREL CRADA RSR2).

14 The NREL-CRADA-RSR2 uses a LI-COR model LI-200 pyranometer; Figure 6 demonstrates the comparison 15 results between the NREL-CRADA-RSR2 (instrument \# 31 in Table 1) and the stand-alone LI-200 (instrument \# 13 16 in Table 1) sensors for GHI irradiance relative to the reference instrument data. The stand-alone LI-200 instrument 17 does not have spectral, angular, or temperature sensitivity corrections. Between the two instruments, there was a 18 clear shift of the probability distribution for the clear-sky condition from negative differences for the LI-200 (Figure $196-$ C) to less and relatively normally distributed differences in GHI from the NREL-CRADA-RSR2 (Figure $6-$ F). 20 However, in the mostly-cloudy sky condition, the probability distribution differences shifted more to the positive 21 MBD for the NREL-CRADA-RSR2. 

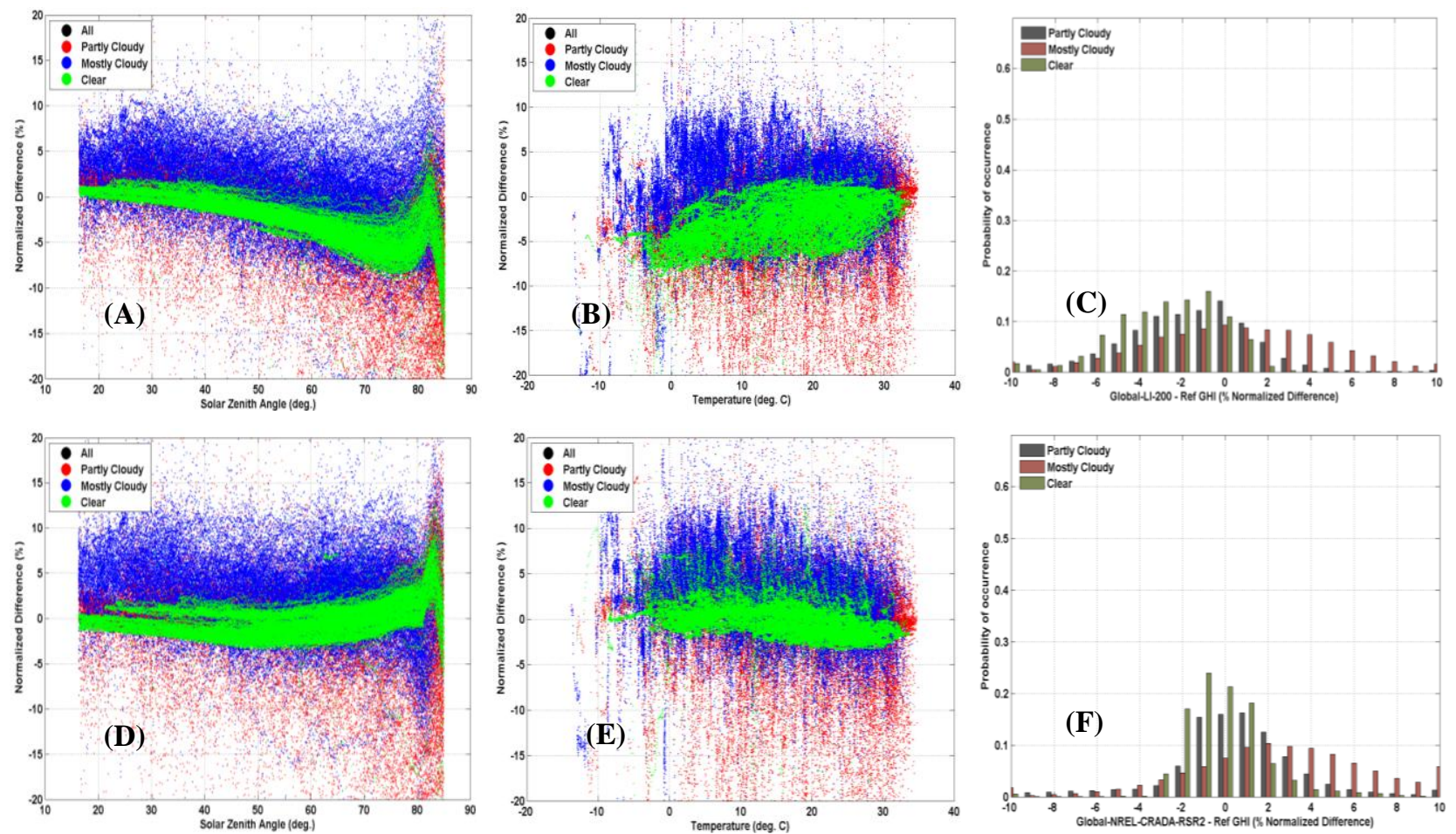

Figure 6. Comparison relative to reference data between the uncorrected silicon photodiode pyranometer LI-200 (top) and corrected silicon photodiode NREL-CRADA-RSR2 (bottom) by solar zenith angle (A\&D) and ambient air temperature $(\mathrm{B} \& \mathrm{E})$, and probability distribution differences $(\mathrm{C} \& \mathrm{~F})$.

As a result of the post-measurement corrections, the temperature and zenith dependencies appeared to be less in the NREL-CRADA-RSR2 (Figure 6 - D) than the stand-alone LI-200 (Figure 6 - A). However, these improvements were more conspicuous for the clear-sky condition than the partly- or mostly-cloudy conditions. Under clear-sky conditions, the NREL-CRADA-RSR2 tended to have better temperature sensitivity (Figure 6 - E) performance than the stand-alone LI-200 (Figure 6-B). This is likely due to the temperature correction algorithm applied in the NREL-CRADA-RSR2 system. Under mostly-cloudy sky conditions, NREL-CRADA-RSR2 did not show much improvement. This could be related to the spectral sensitivity of the sensors in which the instrument is susceptible to changes of broadband spectral distribution by changes of air mass, humidity, clouds, and aerosols (Vignola 2006). The angular response corrections inherent to the NREL-CRADA-RSR2 instrument (Augustyn et al., 2004) appear to correct the so-called "cat ear error" when compared with data from the uncorrected, stand-alone LI200. 
1 this reason, some of the data from thermopile pyranometers have infrared corrections applied to offset this thermal

2 imbalance using coincident infrared or longwave $(4 \mu \mathrm{m}-50 \mu \mathrm{m})$ irradiance measurements from a collocated

3 pyrgeometer. (Note: By design, the Eppley Model 8-48, also called a "black and white" pyranometer, does not

4 exhibit significant thermal offset behaviors. The black (hot) and white (cold) junctions of the thermopile are

5 exposed equally to the effective sky temperature. The absence of a significant thermal offset is reason to use this

6 pyranometer for accurate measurements of DHI.)
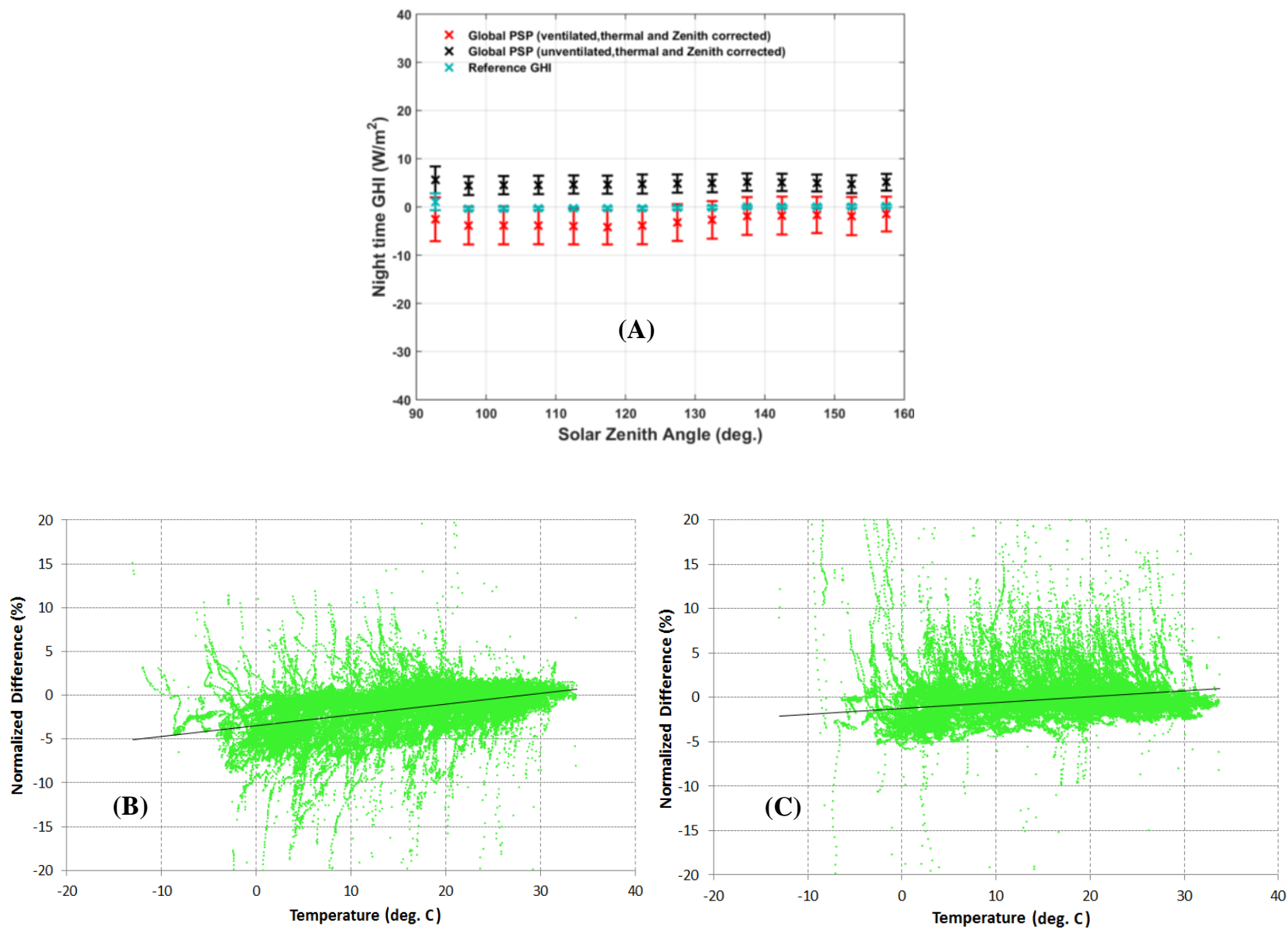

Figure 7. Pyranometer thermal offset characteristics with corrections for ventilated and unventilated compared to reference GHI for selected nighttime solar zenith angle bins under all sky conditions (A) and normalized differences

(UUT minus reference GHI) versus temperature for ventilated (B) and unventilated (C) Eppley Laboratory, Inc., model PSP pyranometers under clear-sky conditions (one-minute data).

One of the Eppley model PSP radiometers in this study is equipped with AC powered ventilator (Figure 7-

12 B) to reduce accumulation of dust, snow, frost, dew, etc., from the dome of the radiometers and to discourage the 13 presence of insects. Although both the Eppley ventilated and unventilated pyranometers were corrected for thermal 14 offset, the ventilator on the ventilated PSP tended to affect the irradiance by creating an additional temperature 15 imbalance between the case and dome of the instrument. This scenario was more apparent during cold ambient 16 temperatures by comparing the number and extent of negative differences in GHI (\%) at air temperatures near 
1 freezing (Figure 7 -B). Usually during overcast skies, the ambient air and sky temperatures are near equilibrium.

2 However, the ventilator was heating the radiometer, which we postulated created an additional exchange of energy

3 between the radiometer and the sky. Kutchenreiter et al., 2014, reported similar claim of pyranometers with AC

4 powered ventilators. This situation ultimately increased the negative bias within the pyranometer. Further, this condition could be exacerbated if the ventilator filter is uncleaned for some time and airflow is restricted. The ventilator effect appeared to be particularly noticeable during nighttime (as shown in Figure 7-A). However, a couple important observations are worth mentioning here. The thermal offset correction for the ventilated PSP was 8 performed using a ventilated Eppley model Precision Infarred Radiometer (PIR). The PSP and PIR share the same case and detector construction details and differ only by the placement of small thermistors for sensing dome and case temperatures and by the use of different domes protecting the thermopile detector. The thermal properties of the two instruments are similar when estimating their heat exchange while ventilated or unventilated. But if the ventilator airflow in both the PIR and the PSP is not equivalent—-for example, because of a difference in the amount of filter obstruction - then the results as shown in Figure 7-B could be due to such an imbalance. On the other hand, we used a ventilated Eppley PIR to correct the unventilated PSP (as shown in Figure 7-C). This correction method stipulates that like ventilation be used to correct both the PIR and the PSP. This could be the reason for an overestimation of irradiance for the unventilated Eppley PSP.

\subsubsection{Asymmetric Installation of Photodiode Detector}

As mentioned above, in addition to routine maintenance of the radiometers, proper installation is critical for

Figure 8. Asymmetric morning and afternoon clear-sky results from the ATI radiometer may be caused by an 26

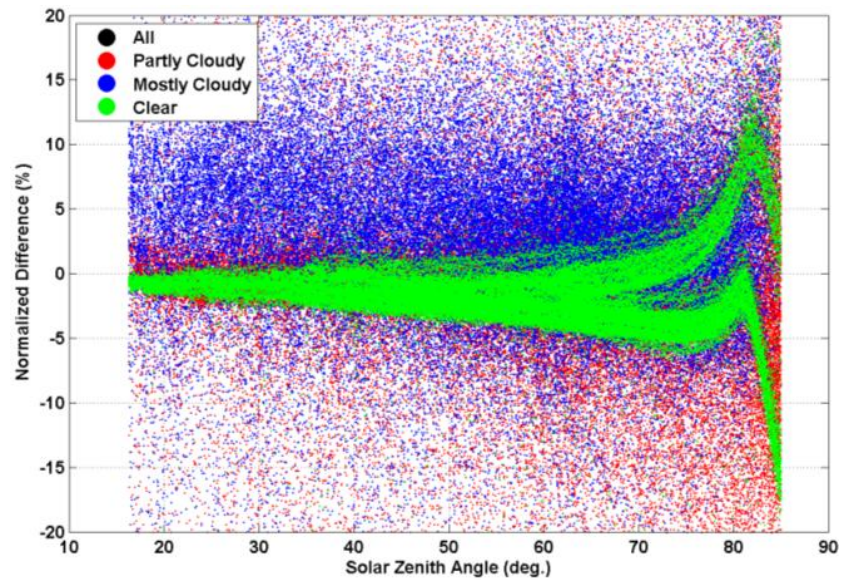
accurate solar irradiance measurements. Imprecise leveling of the instrument or imprecise manufacturing when 20 mounting the detector within the instrument body parallel with the optical plane could cause asymetric responsivity 21 in a radiometer's output throughout the day. This situation is noticeable in the Ascension Technology (ATI) GHI data (Figure 8). Here, the instrument bubble level had been maintained during installation and routine maintenance, so the performance of this UUT could have been affected by an imprecise mounting of the detector itself within the radiometer. unleveled detector. 


\subsubsection{Improper Calibration and Instrument Malfunction}

During the study period, the SPN1 (Delta-T) and SP-110 (Apogee) pyranometers were possibly affected by errors associated with improper calibration and water incursion through the diffuser, respectively.

According to Delta-T, to implement proper calibration for the SPN1 pyranometer, all seven thermopile detectors should be calibrated in unison to be accurately matched so that they give the same output under the same irradiance levels. Further, the manufacturer recommends correlating the SPN1 output to a reference pyranometer. The correlation equation is then used as the pyranometer calibration. However, for this study, we left the internal shading mask in place during BORCAL for comparison with the computed reference irradiance at a solar zenith angle equal to $45^{\circ}$. As a result, only two of the seven thermopile output responsivities were averaged and compared with the BORCAL reference irradiance. This approach results in an adjustment to all sensors based on the calibration average of a subset, and it is possible that dissimilar aging of the seven sensors could account for some of the differences seen in this report.

The Apogee model SP-110 was observed to have occasional water incursions, a situation discussed with the manufacturer. The separation of the diffuser from the main body allows the water droplets to intrude into the detector and instrument interior resulting in erroneous readings for those periods. As a result of these discussions, the manufacturer replaced the original sample with an improved model, but the replacement instrument exhibited the same highly variable sensitivity. For this reason, NREL left the replacement instrument in place as possibly representative of the model in outdoor use. For the study period, we did not try to remove anomalous data points.

Therefore, the higher MBD and RMSD obtained for these pyranometers and calculated DNI from the SPN1 should be read in the context of the above performance limitations.

\subsection{Comparison Result for Direct Normal Irradiance Radiometers}

The reference DNI measurements were taken by a Kipp \& Zonen Model CH1 pyrheliometer traceable to the World Radiometric Reference (WRR) by means of the NREL Transfer Standard Group of electrically selfcalibrating absolute cavity radiometers and the Broadband Outdoor Radiometer Calibration (BORCAL) process. As shown in previous studies (Michalsky et al., 2011, Wilcox and Myers 2008), this reference pyrheliometer has less calibration and measurement uncertainty $(+1.8 \%)$ than the other pyrheliometers described in this report. For this reason, the instrument was chosen as the DNI reference pyrheliometer for our study. The SERI-QC data quality assessment tool was applied to the DNI data set as stated in previous sections by comparing it to other reference diffuse and global measurements. Appendix - Table A.2. contains result statistics of individual DNI radiometers included in the report.

Nineteen DNI data sets were included in this analysis. Some of the instruments calculate the DNI value from measurements of GHI and DHI and others had a direct measurement of DNI. For instance the RSR and SPN1 instruments have a calculated DNI based on measurements of GHI, and DHI. The calculation of DNI was obtained from these two data sets using Equation 1 and solving for DNI. However, Myers (2011) described that the computed DNI from photodiode, such as the RSR instruments produces an approximate $\pm 7 \%$ difference because these instruments are susceptible to spectral sensitivity and the spectral distribution from GHI and DHI. These conditions 
carry forth the greater differences in GHI and DHI to provide larger differences for the calculated DNI when compared with pyrheliometer data.

8 averaging time for the same reasons as those described for the GHI instruments.
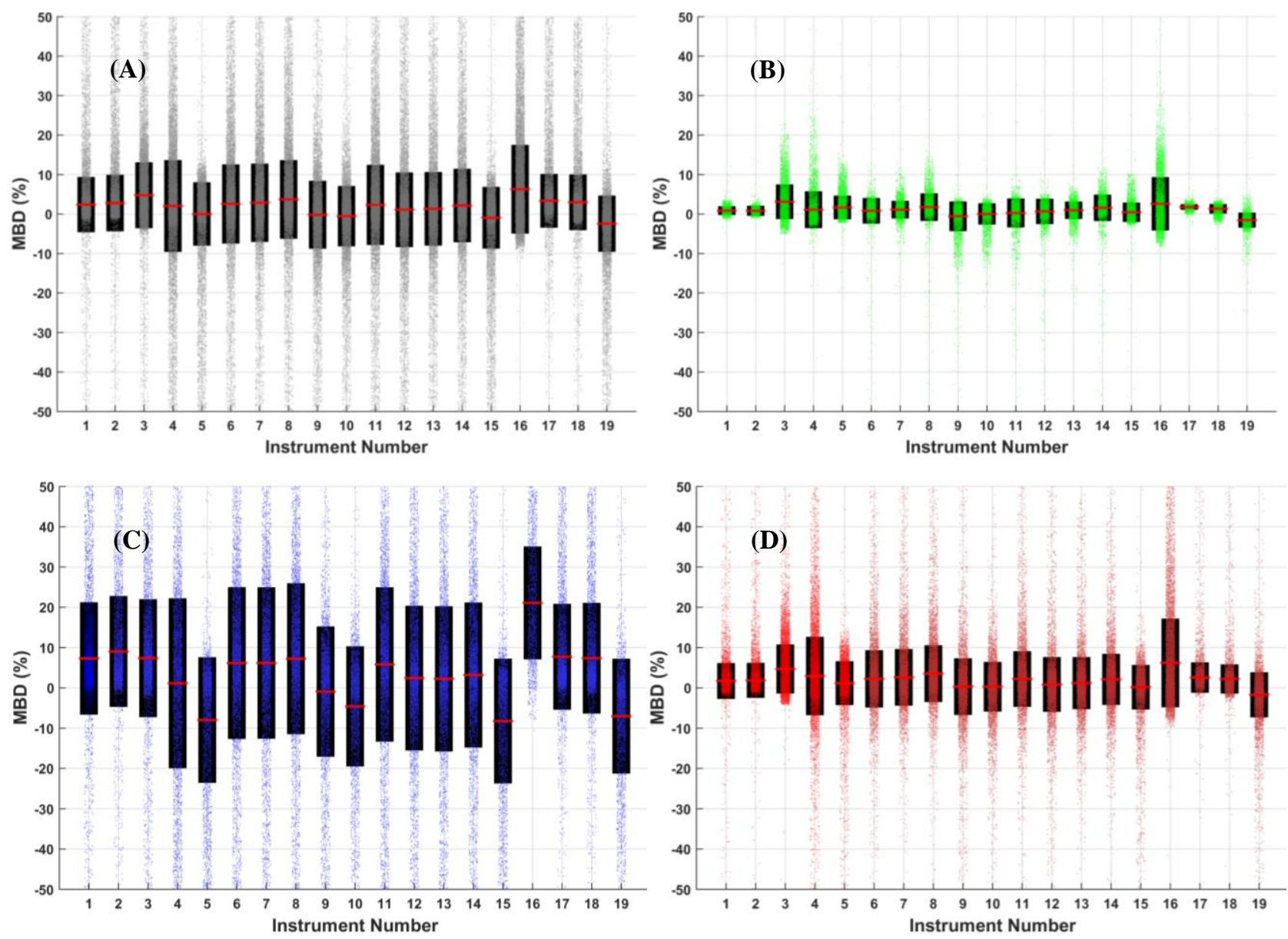

Figure 9. MBD in percent for the 10-minute average for all DNI data under study ((A) all sky, (B) clear sky, (C) mostly cloudy sky, and (D) partly cloudy sky). The red line signifies the mean value of the MBD for the 95\% confidence level. See Table 2 to obtain the instrument name and model by using the instrument number (x-axis). 

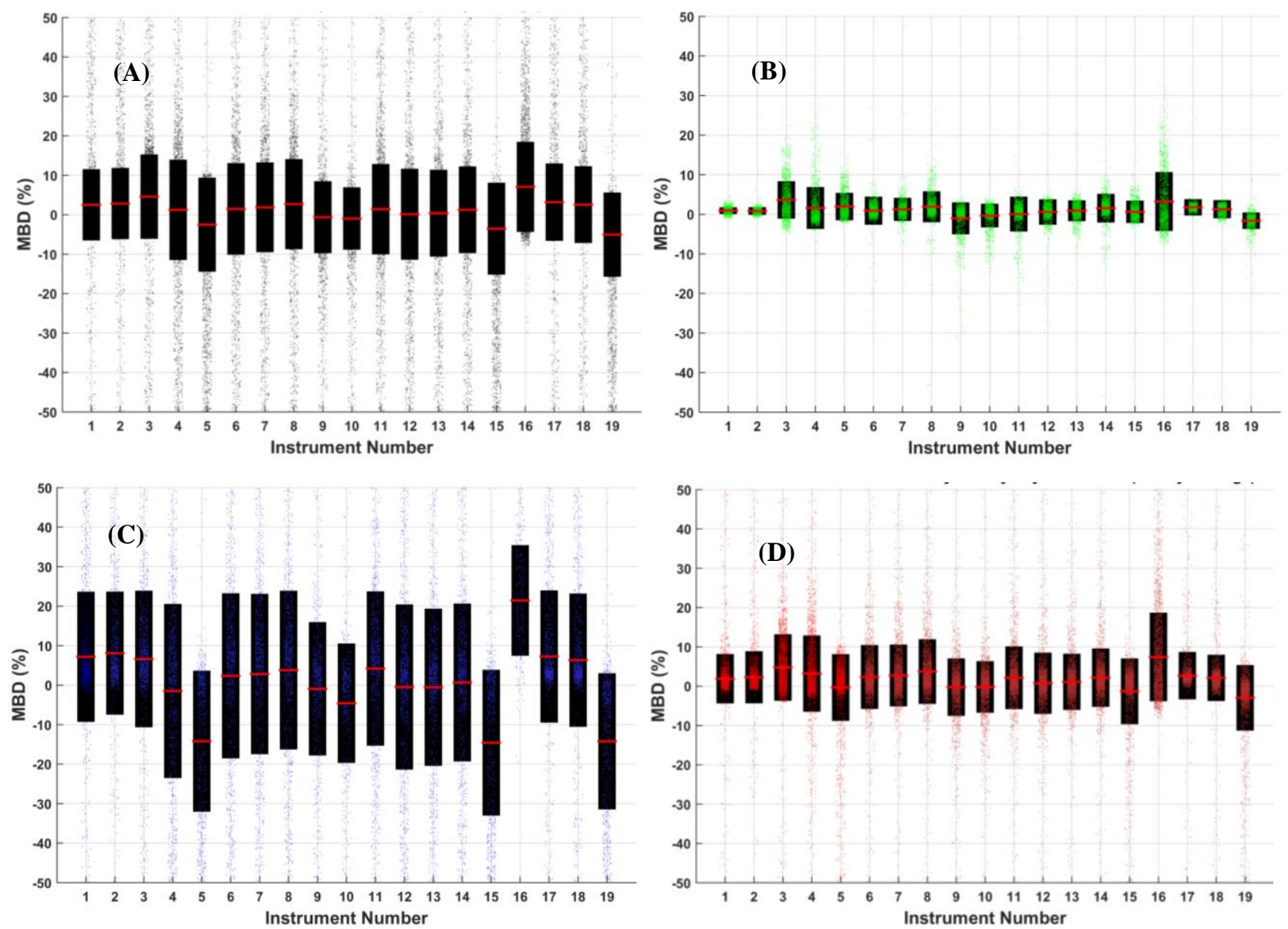

Figure 10. MBD in percent for the hourly average for all DNI data under study ((A) all sky, (B) clear sky, (C) mostly cloudy sky, and (D) partly cloudy sky). The red line signifies the mean value of the MBD for the 95\% confidence level. See Table 2 to obtain the instrument name and model by using the instrument number (x-axis).

Appendix - Table A.2. demonstrates the MBD for all the DNI instruments under clear and mostly-cloudy conditions. The differences were divided in various solar zenith angle ranges. Solar zenith angle dependence is not likely for pyrheliometers (Wilcox, 2008) and data in the table for those radiometers may not be significant; however, rotating shadowband instruments that calculate DNI from GHI and DHI will demonstrate a difference correlation with zenith angle. As described in the GHI section, some of the outliers that were close to the $\pm 100 \% \mathrm{MBD}$ limit might have skewed the outcome in Appendix - Table A.2., especially data from the high solar zenith angle and partly- or mostly-cloudy conditions. These higher deviations could have been a result of fast-moving clouds accompanied by differing fields of view (Vignola et al., 2012), for example calculated DNI for the RSR and the reference pyrheliometer. Further, the RSR radiometers with computed DNI from DHI and GHI are susceptible to spectral effects relating to the optical transmittance of the diffusers as well as the limited spectral range of the detectors. Therefore, temperature dependency, differing fields of view, differing instrument response characteristics, and solar zenith angle dependency can cause disagreements between the UUT and the reference pyrheliometer. 

exclusion threshold was $\pm 100 \%$ MBD.

Note: In Appendix - Table A.2., yellow highlighted values are MBD greater than $\pm 5 \%$ and the data

The RMSD results suggest that under clear-sky conditions, all the DNI data from the UUT radiometers agreed relatively well with the reference instruments (Figure 11). However, under partly- and mostly-cloudy sky conditions, factors such as temporal responsivity and field of view of the radiometers can result in higher RMSD\%.

6 Also consider that much of the DNI data in the mostly-cloudy conditions had a small magnitude, resulting in 7 unrealistically large ratios while the actual difference in solar irradiance is quite small. This can be confirmed by 8 noting in Appendix - Table A.2. that most of the highlighted percent values (outside of $\pm 5 \%$ ) are associated with 9 small irradiance values, typically less than $5 \mathrm{~W} / \mathrm{m}^{2}$. Users should take this into account when considering the 10 mostly-cloudy conditions presented in Appendix - Table A.2.
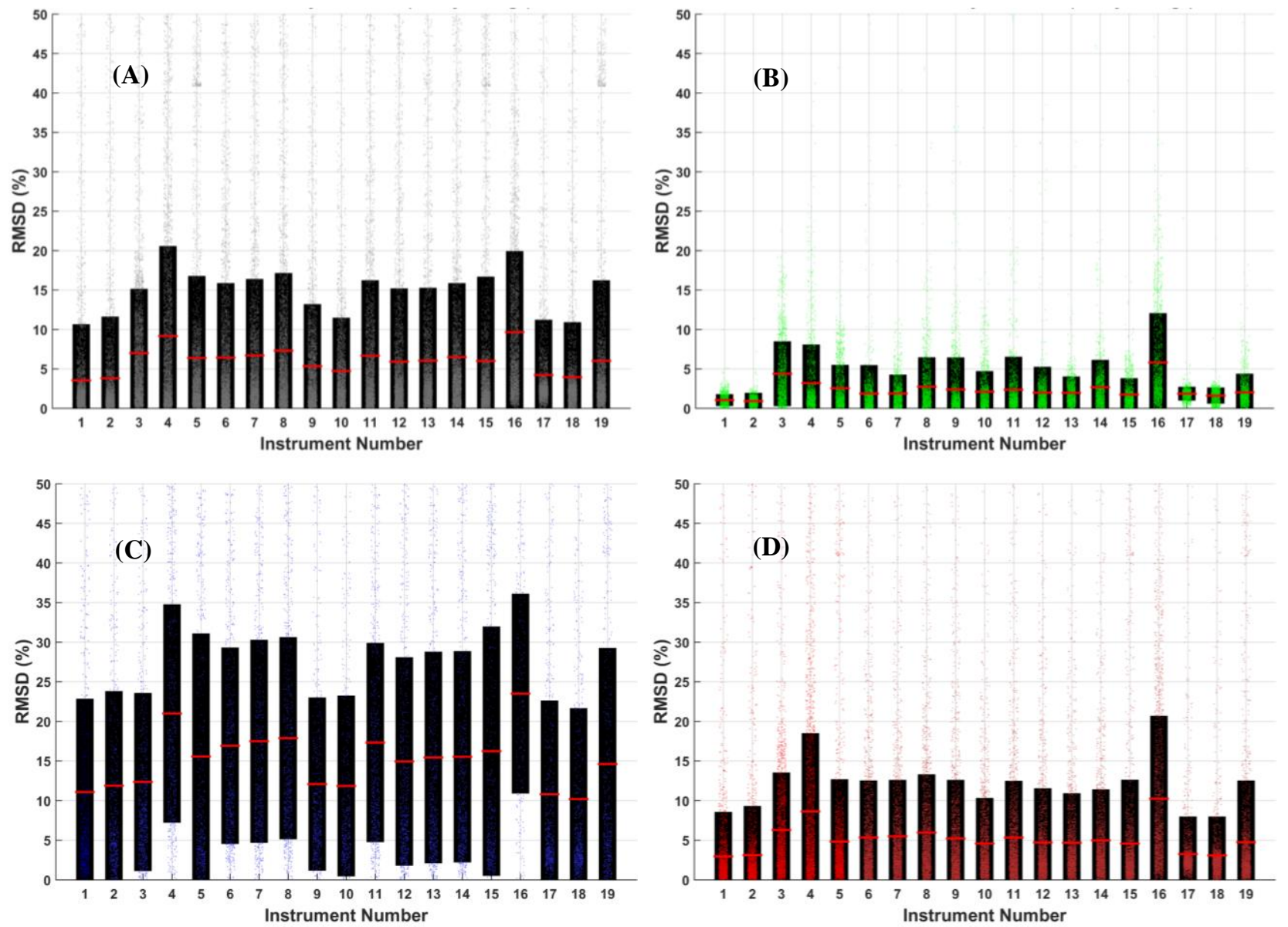

Figure 11. RMSD in percent for the hourly average for all DNI data under study ((A) all sky, (B) clear sky, (C) mostly cloudy sky, and (D) partly cloudy sky). The red line signifies the mean value of the RMSD for the 95\% confidence level. See Table 2 to obtain the instrument name and model by using the instrument number (x-axis).

\subsubsection{Effect of Ambient Temperature on the Sensitivity of the Pyrheliometers}

The DNI thermopile radiometers (pyrheliometers) have temperature dependencies similar to the GHI thermopile pyranometers. For instance, one-minute data from the Hukseflux radiometer model number DR108068 
1 had relatively more evident temperature dependency than model number DR108066 (Figure 12). The two Eppley

2 model NIP radiometers tended to have less temperature dependency, especially at ambient air temperatures below

$320^{\circ} \mathrm{C}$. The two NIPs and the two Hukseflux radiometers did not have the temperature correction applied in this

4 study. However, a previous study that included the Hukseflux pyrheliometers showed that the manufacturer's

5 temperature correction curve for these instruments reduced temperature error to a much lower magnitude which

6 allowed the pyrheliometers to perform among the top non-cavity pyrheliometers (Michalsky et al., 2011).
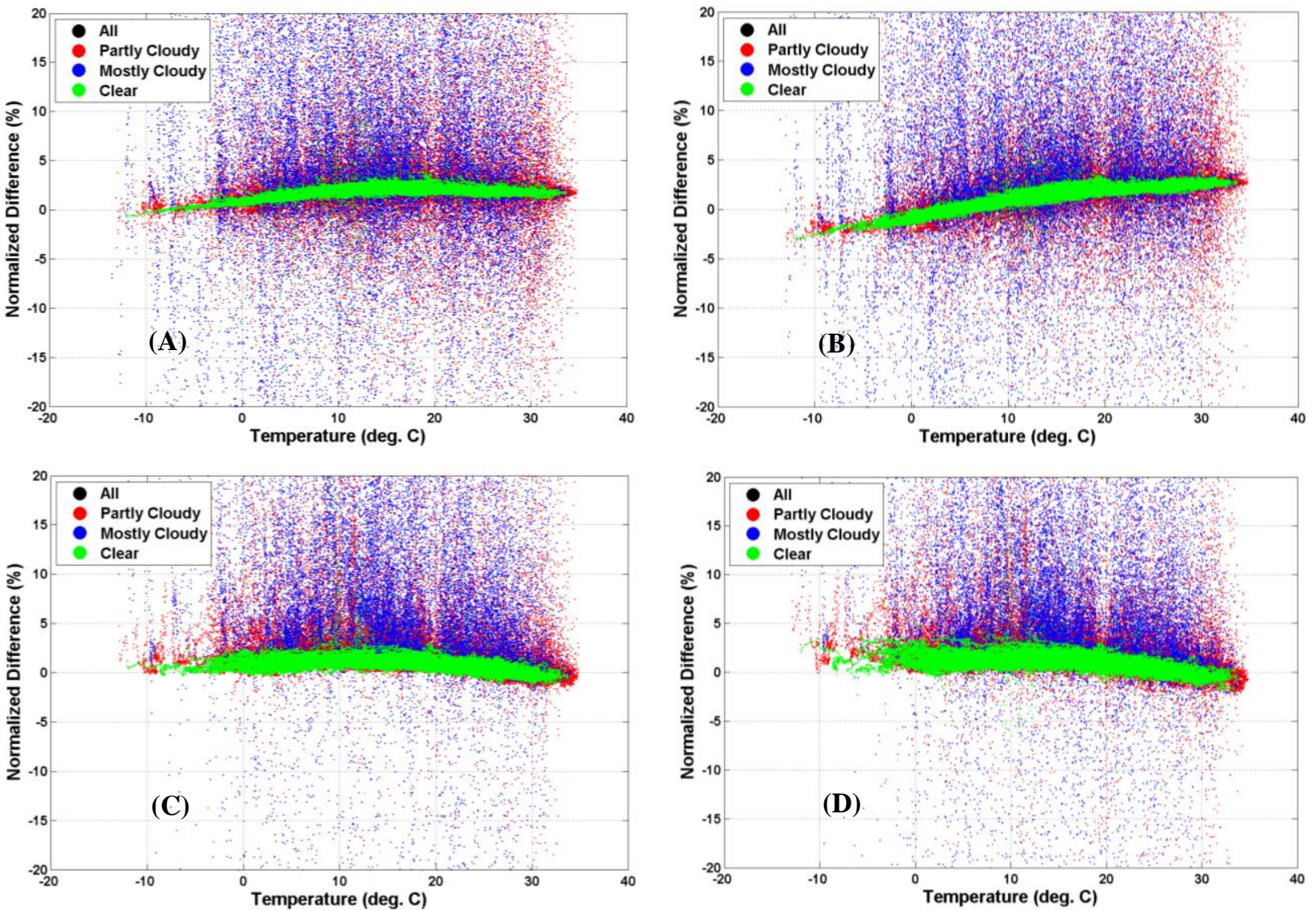
7 Figure 12. Effect of temperature on DNI measurement (A) Hukseflux radiometer serial number DR108066, (B)
8 Hukseflux radiometer serial number DR108068, (C) Eppley Laboratory, Inc. NIP (Table 2 Instrument \#2) and (D)
Eppley Laboratory, Inc. NIP (Table 2 Instrument \#1)

10

11

12

13

14

15

16

17

\subsection{Thermopile versus Photodiode Radiometers}

The design of commercially available pyranometers and pyrheliometers for measuring broadband solar irradiance is generally based on the principles of thermoelectric or photoelectric detectors. The cost/performance characteristics of these radiometers must meet user needs consistent with the intended application and the desired data uncertainty limits. As previously introduced, the inherent measurement performance characteristics of these radiometers differ according to various response characteristics. Thermopile-based radiometers have a wide-band thermopile detector ( $280 \mathrm{~nm}$ to $2,800 \mathrm{~nm}$ ) with flat spectral response for most of the solar spectrum and they are equipped with precision-ground glass or sapphire domes to protect the detector. They also exhibit thermal offsets 
due to prevailing net infrared radiation conditions at time of measurement and their measurements can be corrected for temperature, and thermal offset response characteristics. On the other hand, photodiode-based radiometers have limited spectral response ranges; typically about $75 \%$ of the full solar spectrum, non-uniform spectral response, and 4 varying temperature and angular response characteristics, depending on their design. Photodiode-based radiometers have the fastest time responses, exhibit no thermal offsets, and their measurements can be corrected for spectral, angular, and temperature response characteristics. Furthermore, the characteristics of photodiode radiometers will have an effect on the spectral power distribution of the total global horizontal and diffuse horizontal irradiance which in-turn can impact the calculated direct normal irradiance data. Various methods are available for correcting known measurement performance limitations of photodiode-based radiometers. Additionally, the responsivity of each thermopile or photodiode radiometer of the same model could differ depending on the environmental conditions. Each instrument, whether a photodiode or thermopile model, should be treated independently based on the instrument's performance and/or the manufacturer's specifications. In general terms, the results here show that the best of the thermopile instruments performed better than the best of the silicon instruments, but there were some silicon instruments that performed better than some of thermopile instruments. Actual instrument choice should take these results into consideration, along with acquisition and installation costs, desired measurement uncertainty, and availability of resources for maintenance.

\subsection{Recent Advances in Radiometry}

The historically small commercial market for radiometers has limited the manufacturers' interests to significantly improve their products. The increasing number and size of solar energy conversion systems has now created more opportunities and demands for improvements to radiometry. In these new circumstances, there are various groups including the manufacturers of radiometers, working to improve measurement performance and harmonize the methodology for acquiring radiometric data. These improvements will be based on customer feedback, government research (NREL, National Oceanic and Atmospheric Administration (NOAA), National Institute of Standards and Technology (NIST), et al.), international standard development groups such as, the International Organization for Standardization (ISO), American Society for Testing Materials (ASTM International), the International Energy Agency (IEA - Task 46), and the needs/requirements of the solar and utility industries. The focus to improve radiometer design will require identifying the more significant contributors to measurement uncertainty and change their instrument design and manufacturing accordingly. Although improvements in instrumentation are an important focus in the long term, environmental or operational issues (soiling, precipitation, tracking errors, and inadequate maintenance) are usually a far greater contributor to solar measurement error than instrument design. This makes improvements in operational protocols an immediate candidate for reducing measurement uncertainty.

\section{4. SUMMARY}

Accurate solar resource measurements are essential for determining system efficiencies of solar energy conversion installations, developing improved satellite-based models for estimating solar resources, and validating 
and direct normal irradiance (GHI and DNI) was made based upon measurements for the period 1 April 2011 through 31 March 2012 at the Solar Radiation Research Laboratory (SRRL) in Golden, Colorado, USA. This report helps differentiate the similarities and differences among DNI and GHI radiometers when compared to the reference data set with the lowest estimated measurement uncertainties of the corresponding measurement type. As a whole, the instruments were most similar when the solar zenith angle was below 60 degrees and there was a clear-sky condition. The comparisons with reference data showed that the differences among the measurement data from the participating instruments were within $\pm 5 \%$ for both GHI and DNI. At higher solar zenith angles (greater than 60 degrees), the GHI differences under mostly- and clear-sky conditions went up to $\pm 17 \%$. Further, at higher solar zenith angles, mostly-cloudy conditions demonstrated higher percentage differences, up to $\pm 40 \%$ for DNI on very few instruments. Some of these differences are a result of varying time response, spectral irradiance distribution responses, angular response, thermal offset, and temperature sensitivity. Further, the ventilators (especially AC powered) used on some of the instruments exacerbated the differences between the reference and the test instruments. Post-measurement corrections applied to some instruments, such as zenith and temperature correction, appeared to lessen the differences with respect to the reference irradiance, e.g. the NREL-CRADA-RSR2 LICOR GHI data shown a reduction by as much as $\pm 2 \%$. Previous studies and NREL calibration reports shown individual radiometer responsivity $\left(\mu \mathrm{V} / \mathrm{Wm}^{-2}\right)$ varies with the range of solar zenith angles achieved at SRRL. Therefore, applying responsivity as a function of solar zenith angle could show significant reduction in the differences from the reference value. One important note is that data from all radiometers were normalized to minimize effects attributed to differing calibration methods and results, and the normalization factor is not intended to modify results reported elsewhere. Further, this approach did not address differences in calibration methods and the specific calibration factors used for each instrument; there is on-going investigation to address this issue. We also tried to investigate the measurement differences versus various environmental parameters, such as temperature and wind speed. There were noticeable temperature correlation events for some of the radiometers, but wind speed did not show significant correlation as a result of the analyses. Overall, the interpretation of the differences (MBD and/or RMSD) should be read in the context that reference instrument and data logger uncertainties were not included in the reported values; therefore, the differences among the reference and test instruments could move up and down by the uncertainty magnitude ( $\pm 2.6 \%$ and $\pm 1.8 \%$ for reference GHI and DNI, respectively) and may not be significant within these uncertainty intervals.

Furthermore, through research and development, instrument manufacturer and research institutions continue to improve radiometer measurement performance by tackling the major sources of uncertainty to the radiometric data. The sources of uncertainties differ by radiometer type and model. Therefore, users are advised to understand the context of the results described in this paper when choosing radiometers for their specific application.

\section{ACKNOWLEDGEMENTS}

34 This work was supported by the U.S. Department of Energy under Contract No. DE-AC36-08GO28308 with the 35 National Renewable Energy Laboratory. The U.S. Government retains and the publisher, by accepting the article for 36 publication, acknowledges that the U.S. Government retains a nonexclusive, paid-up, irrevocable, worldwide license 
2 Andreas, A.; Stoffel, T.; (1981). NREL Solar Radiation Research Laboratory (SRRL): Baseline Measurement

3 System (BMS); Golden, Colorado (Data); NREL Report No. DA-5500-56488. http://dx.doi.org/10.5439/1052221

4 Augustyn, J.; Geer, T.; Kern, E.; Little, R.; Stoffel, T.; Vignola, F.; Kessler, R.; Boyson, B. (2004). "Update of

5 Algorithm to Correct Direct Normal Irradiance Measurements Made With a Rotating Shadowband Pyranometer."

6 Campbell-Howe, R. ed. American Solar Energy Society Solar Conference Proceedings, Including Proceedings of the

7 33rd American Solar Energy Society Annual Conference and Proceedings of the 29th National Passive Solar

8 Conference; July 11-14, 2004, Portland, Oregon. Boulder, CO: American Solar Energy Society; pp. 295-300.

9 NREL/CP-560-38328. Golden, CO: National Renewable Energy Laboratory.

10 Fröhlich, C., (1977). 'World Radiometric Reference', in: WMO/CIMO Final Report, WMO No. 490, 97-110.

11 (PMOD/WRC intern: 545a).

12 Fröhlich, C., (1991). History of solar radiometry and the World Radiation Reference, Metrologia 28, 111-115.

13 (PMOD/WRC intern: 650).

14 Habte, A.; Wilcox, S.; Stoffel, T. (2015). Evaluation of Radiometers Deployed at the National Renewable Energy

15 Laboratory's Solar Radiation Research Laboratory. 187 pp.; NREL Report No. NREL/TP-5D00-60896. Golden,

16 CO: National Renewable Energy Laboratory.

17 Habte, A.; Sengupta, M.; Reda, I.; Andreas, A.; Konings, J. Calibration and Measurement Uncertainty Estimation of 18 Radiometric Data. Preprint. NREL/CP-5D00-62214. Golden, CO: National Renewable Energy Laboratory, 2014; 9 19 pp.

20 Joint Committee for Guides in Metrology (JCGM). 2008. Evaluation of measurement data - Guide to the expression 21 of uncertainty in measurement. GUM 1995 with minor revisions. Bureau Interational des Poids et Mesures.

22 Available at: http://www.bipm.org/en/publications/guides/gum.html

23 King, D.L.; Myers, D.R. (1997). "Silicon-Photodiode Pyranometers: Operational Characteristics, Historical 24 Experiences, and New Calibration Procedures." 26th Institute of Electrical and Electronics Engineers Photovoltaic 25 Specialists Conference Proceedings; Sept. 29-Oct. 3, Anaheim, California.

26 Kutchenreiter, M.; Gotseff, P.; Habte, A.; Reda, I.; Sengupta, M.; Andreas, A.; Anderberg, M., 2014,Evaluation of 27 DC Ventilator Fans Proposed for Pyranometer Measurements in the ARM Program (Poster). NREL (National 28 Renewable Energy Laboratory) NREL/PO-5D00-61523

29 Maxwell, E.; Wilcox, S.; Rymes, M. (1993). Users Manual for SERI_QC Software: Assessing the Quality of Solar 30 Radiation Data. NREL/TP-463-5608. Golden, CO: National Renewable Energy Laboratory.

31 http://www.nrel.gov/docs/legosti/old/5608.pdf

32 Michalsky, J.J., et al. (2011). "An Extensive Comparison of Commercial Pyrheliometers Under a Wide Range of 33 Routine Observing Conditions.” Journal of Atmospheric and Oceanic Technology (28); pp. 752-766. 
1 Michalsky, J.J.; Harrison, L.; Lebaron, B.A. (1987). "Empirical Radiometric Correction of a Silicon Photodiode

2 Rotating Shadowband Pyranometer." Solar Energy 39(2); pp. 87-96.

3 Myers, D.R.; T. L Stoffel; Andreas, A.; Wilcox, S.; Reda, I. (2000). Improved Radiometric Calibrations and

4 Measurements for Evaluating Photovoltaic Devices. NREL/TP-520-28941. Golden, CO: National Renewable

5 Energy Laboratory.

6 Myers, D.R., (2011). "Quantitative Analysis of Spectral Impacts on Silicon Photodiode Radiometers.” American

7 Solar Energy Society Solar Conference Proceedings; May 17-20, Raleigh, North Carolina. Boulder, CO: American

8 Solar Energy Society.

9 Myers, D.R. (2013). Solar Radiation: Practical Modeling for Renewable Energy Applications. Boca Raton, FL: CRC 10 Press, Taylor and Francis Group.

11 Myers, D.R.; Andreas, A.; Stoffel, T.; Reda, I.; Wilcox, S.; Gotseff, P.; Kay, B. (2001). "Radiometric Calibrations, 12 Measurements, and Standards Development at NREL." NCPV Program Review Meeting Proceedings; Oct. 14-17, 13 Lakewood, Colorado. NREL/CP-560-30964. Golden, CO: National Renewable Energy Laboratory.

14 Reda, I. (1998). Improving the Accuracy of Using Pyranometers to Measure the Clear Sky Global Solar 15 IrradianceNREL/TP-560-24833. http://www.nrel.gov/docs/legosti/fy98/24833.pdf

16 Reda, I. (2011). Method to Calculate Uncertainties in Measuring Shortwave Solar Irradiance Using Thermopile and 17 Semiconductor Solar Radiometers. NREL/TP-3B10-52194. Golden, CO: National Renewable Energy Laboratory.

18 Sengupta, M; A Habte; S Kurtz; A Dobos; S Wilbert; E Lorenz; T Stoffel; D Renne; C Gueymard; D Myers; S

19 Wilcox; P Blanc; R. Perez (2015). Best Practices Handbook for the Collection and Use of Solar Resource Data for 20 Solar Energy Applications. NREL/TP-5D00-63112. Golden, CO: National Renewable Energy Laboratory.

21 http://www.nrel.gov/docs/fy15osti/63112.pdf

22 Stoffel, T.; Reda, I. (2013). National Renewable Energy Laboratory Pyrheliometer Comparisons: 24 September-5

23 October 2012 (NPC-2012). NREL/TP-5500-58430. Golden, CO: National Renewable Energy Laboratory.

24 Vignola, F. "Removing Systematic Errors from Rotating Shadowband Pyranometer Data." (2006). American Solar 25 Energy Society Solar Conference Proceedings; July 9-13, Denver, Colorado. Boulder, CO: American Solar Energy 26 Society.

27 Vignola, F.; Stoffel, T.; Michalsky, J.J. (2012). Solar and Infrared Radiation Measurements. Boca Raton, FL: CRC 28 Press, Taylor and Francis Group.

29 Wilcox, S.M.; Myers, D. (2008). Evaluation of Radiometers in Full-Time Use at the National Renewable Energy 30 Laboratory Solar Radiation Research Laboratory. NREL/TP-550-44627. Golden, CO: National Renewable Energy 31 Laboratory. 


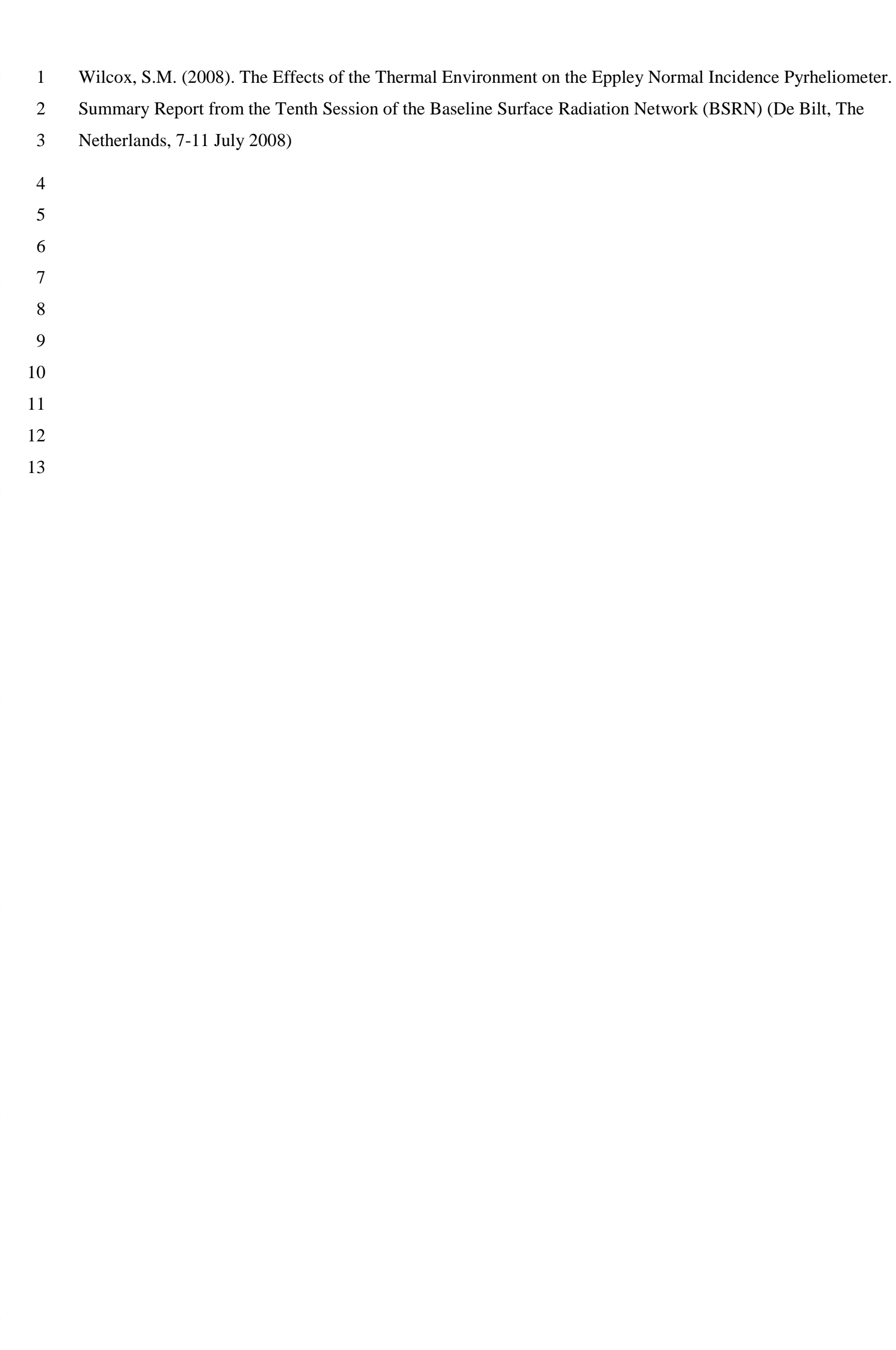

